\title{
Evaluation of the Knowledge of Iranian Pedodontists in Relation to Cases Requiring Early Orthodontic Treatment: A Cross Sectional Study
}

\author{
Amin G ${ }^{1}$, Zeynab ${ }^{2}$, Mohadeseh $\mathrm{D}^{3 *}$ and Gholamreza $\mathrm{E}^{4}$ \\ ${ }^{1}$ Department of Orthodontic, Kermanshah University of Medical Sciences, Iran \\ ${ }^{2}$ Students research committee, Kermanshah University of Medical Sciences, Iran \\ ${ }^{3} \mathrm{MS}$ in Orthodontics, Kerman University of Medical Sciences, Iran \\ ${ }^{4}$ Department of Orthodontic, Shahed University, Iran
}

Review Article

Volume 4 Issue 4

Received Date: December 07, 2019

Published Date: December 30, 2019

DOI: $10.23880 /$ oajds-16000242

*Corresponding author: Mohadeseh Delavarian, DDS, MS in Orthodontics, Kerman University of Medical Sciences, Kerman, Iran, Email: m66.delavarian@gmail.com

\section{Abstract}

Early orthodontic treatment deals with problems such as posterior crossbite and $\mathrm{Cl} \mathrm{III} \mathrm{malocclusion} \mathrm{and} \mathrm{it} \mathrm{is} \mathrm{important} \mathrm{to}$ diagnose such cases and render proper treatment or refer the patients to an orthodontists at a proper time to carry out early orthodontic treatment. In the present descriptive/cross-sectional study, the knowledge of pedodontists in Iran in relation to cases requiring early orthodontic treatment were evaluated with two open questions. Of 120 pedodontists to whom the questionnaires had been sent, 54(45\%) returned the questionnaires. The responses in the questionnaires were evaluated by two experienced orthodontists and the questionnaires were scored based on the criteria. The majority of pedodontists in the present study (87\%) achieved a knowledge score in the range of 4-9 (poor to moderate), indicating their need for education in orthodontic problems in children, diagnosis and referral of the patients requiring orthodontic treatment.

Keywords: Post crossbite; Cl III malocclusion; Early orthodontic treatment; Knowledge of pedodontist

\section{Introduction}

One of the subjects taught in the pediatric specialty in Iran is 'early orthodontic treatment', which is a component of the related courses and discusses the reciprocal relationship with orthodontics specialty.

Early orthodontic treatment during the deciduous or mixed dentition periods is undertaken to promote tooth and skeletal developments before eruption of permanent teeth [1]. Therefore, the American Academy of Orthodontists recommends that children should be examined at 7 years when the permanent teeth begin to erupt and this age is the best age for orthodontic counselling [1].

Early orthodontic treatment deals with problems such as posterior crossbite and $\mathrm{Cl}$ III malocclusion, which are 


\section{Open Access Journal of Dental Sciences}

frequently encountered by general dental practitioners or pedodontists in the clinic. It is important to diagnose such cases and render proper treatment or refer the patients to an orthodontists at a proper time to carry out early orthodontic treatment because it increase the chances of success $[2,3]$, thereby decreasing the need for complex orthodontic treatments and surgery in future [4].

Studies have shown that if $\mathrm{Cl}$ III malocclusion is treated during the deciduous dentition period, there will be a greater decrease in protrusion and in the length of the mandible, with more skeletal changes in the maxilla [5].

The most frequent form of posterior crossbite is the unilateral type, which is produced by the functional shift of the mandible and its main etiologic factor is the narrowness of maxilla [6,7]. Several studies have reported that crossbites do not resolve spontaneously and can give rise to TMJ disorders. Adaptation of the skeleton, dentition and muscles with the mandibular shift at a young age and the difficulty of treatment at older ages and the need for surgery in association with orthodontic treatment are the reasons for undertaking early treatment [1].

\section{Methods and Materials}

In the present descriptive/cross-sectional study, the knowledge of pedodontists in Iran in relation to cases requiring early orthodontic treatment were evaluated. The subjects consisted of 120 pedodontists who had graduated from different universities in Iran during the past 15 years. To this end, a questionnaire was designed with two open questions consisting of several parts. Question 1 dealt with the history and chief complaint of an 8-year-old boy with Cl III malocclusion in association with two questions on the diagnosis and the suggested treatment plan. Question 2 dealt with the history and chief complaint of an 8-year-old girl with posterior crossbite malocclusion and the functional shift of the mandible in association with 3 questions on the diagnosis and the suggested measures. To help diagnose the problem of each case, 2 intraoral photos (occlusion from the front and occlusion from the right) and 3 extraoral photos (the frontal view at rest, the frontal view during smiling and the profile view at rest) were presented.

\section{Results}

Of 120 pedodontists to whom the questionnaires had been sent, $54(45 \%)$ returned the questionnaires. The responses in the questionnaires were evaluated by two experienced orthodontists and the questionnaires were scored based on the following criteria:

- Wrong diagnosis or treatment plan: a score of zero for each

- Incomplete diagnosis or treatment plan: a score of 1 for each

- Correct diagnosis or treatment plan: a score of 2 for each

- Correct diagnosis or treatment plan in association with explaining the details of examinations and the appliances needed: a score of 3 for each

Then based on the total sum of the knowledge scores, the subjects were assigned to 5 groups as follows:

$0-3$ : very poor

4-6: poor

7-9: moderate

10-12: good

13-15: very good

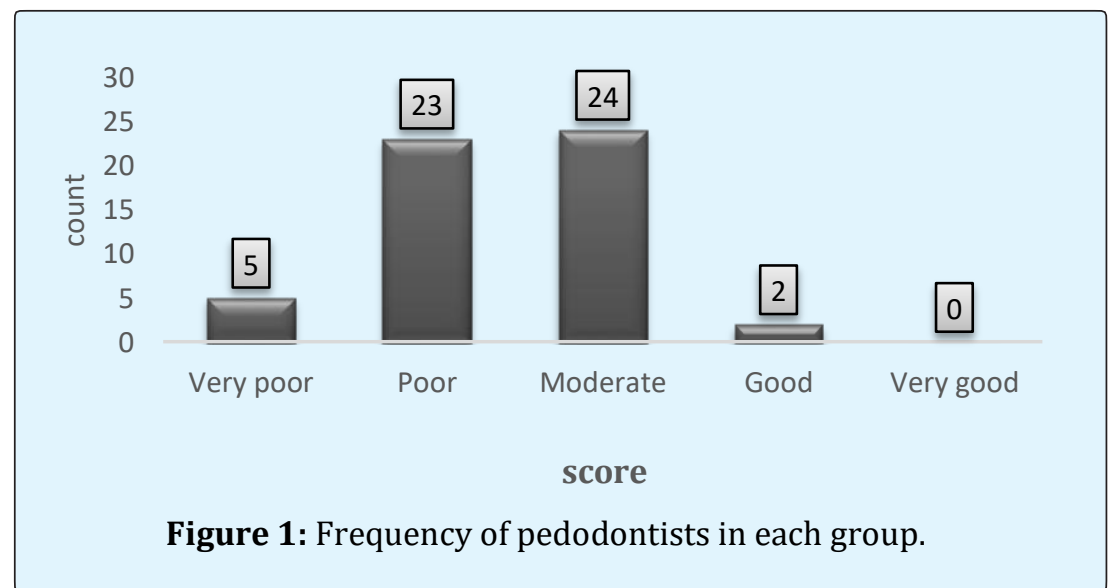

Mohadeseh D, et al. Evaluation of the Knowledge of Iranian Pedodontists in Relation to Cases Requiring Early Orthodontic Treatment: A Cross Sectional Study. J Dental Sci 2019, 4(4): 000242. 


\section{Open Access Journal of Dental Sciences}

Evaluation of knowledge of pedodontists showed a mean score of 6.05 (a range of 5.45-6.64) out of a total score of 15 . The results showed that 5 subjects (9.3\%) were in the very poor group; 23 (42.6\%) were in the poor group; 24 (44.4\%) were in the moderate group; and 2 (3.7\%) were in the good group. No one succeeded in achieving a score of very good. The differences were significant statistically (Figure 1).

\section{Discussion}

The majority of pedodontists in the present study $(87 \%)$ achieved a score in the range of $4-9$ (poor to moderate), indicating their need for education in orthodontic problems in children, diagnosis and referral of the patients requiring orthodontic treatment. the factors responsible for such a situation might be lack of studying the relevant references and lack of the pedodontists' sensitivity to early treatment and referral of such patients to orthodontists. In general, it appears it is necessary to improve the knowledge of pedodontists in Iran about early orthodontic treatment. Therefore, it is recommended that continuous education problems be presented or the educational curricula be improved to solve such a problem.

\section{References}

1. Prabhakar RR, Saravanan R, Karthikeyan M, Vishnuchandran C (2014) Prevalence of malocclusion and need for early orthodontic treatment in children. J Clin Diagn Res 8(5): 60-61.
2. Piero A (2006) Interceptive orthodontics-the need for early diagnosis and treatment of posterior crossbites. Med Oral Patol Oral Cir Bucal 11(2): 210-214.

3. Baccetti T, McGill JS, Franchi L, McNamara JA, Tollaro I (1998) Skeletal effects of early treatment of Class III malocclusion with maxillary expansion and face-mask therapy. Am J Orthod Dentofacial Orthop 113(3): 333343.

4. Shalish M, Gal A, Brin I, Zini A, Ben-Bassat Y (2012) Prevalence of dental features that indicate a need for early orthodontic treatment. Eur J Orthod 35(4): 454459.

5. Baccetti T, Baccetti T, Tollaro I, Tollaro I (1998) A retrospective comparison of functional appliance treatment of Class III malocclusions in the deciduous and mixed dentitions. Eur J Orthod 20(3): 309-317.

6. Lenguas L, Alarcón J-A, Venancio F, Kassem M, Martín C (2012) Surface electromyographic evaluation of jaw muscles in children with unilateral crossbite and lateral shift in the early mixed dentition. Sexual dimorphism. Med Oral Patol Oral Cir Buccal 17(6): 1096-1102.

7. Kennedy DB, Osepchook M (2005) Unilateral posterior crossbite with mandibular shift: a review. J Can Dent Assoc 71(8): 569-573. 